Fall 11-20-2018

\title{
Overcoming Exposure to Complex Stressors: An Examination of Protective Coping Mechanisms for Low-Income Urban African American Youth
}

Molly Cory

DePaul University, mcory@crimson.ua.edu

Follow this and additional works at: https://via.library.depaul.edu/csh_etd

Part of the Child Psychology Commons, and the Clinical Psychology Commons

\section{Recommended Citation}

Cory, Molly, "Overcoming Exposure to Complex Stressors: An Examination of Protective Coping Mechanisms for Low-Income Urban African American Youth" (2018). College of Science and Health Theses and Dissertations. 311.

https://via.library.depaul.edu/csh_etd/311

This Thesis is brought to you for free and open access by the College of Science and Health at Digital Commons@DePaul. It has been accepted for inclusion in College of Science and Health Theses and Dissertations by an authorized administrator of Digital Commons@DePaul. For more information, please contact digitalservices@depaul.edu. 
Overcoming Exposure to Complex Stressors: An Examination of Protective Coping Mechanisms for Low-Income Urban African American Youth

\author{
A Thesis \\ Presented in \\ Partial Fulfillment of the \\ Requirements for the Degree of \\ Master of Arts \\ By \\ Molly Frances Cory \\ November, 2018 \\ Department of Psychology \\ College of Science and Health \\ DePaul University \\ Chicago, IL
}




\section{Thesis Committee}

Kathryn Grant, Ph.D., Chairperson

Jocelyn Carter, Ph.D. 


\section{Biography}

The author was born in Hayward, California, March 28, 1994. She graduated from Irvington High School in Fremont, California. She received her Bachelor of Science degree from the University of Alabama in 2012, and her Master of Arts degree in Psychology from DePaul University in 2018 . 


\section{Table of Contents}

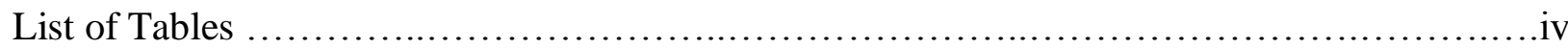

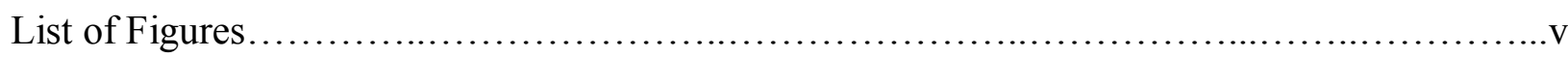

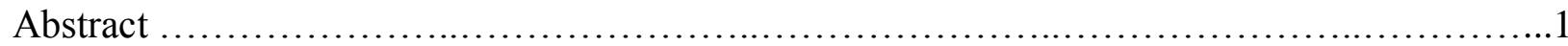

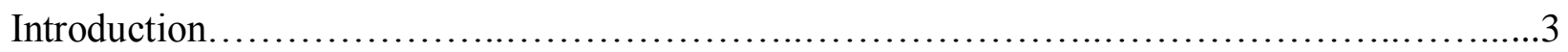

Rationale................................................................11

Statement of Research Questions.............................................. 12

Method......................................................................... 13

Participants..............................................................

Setting ................................................................

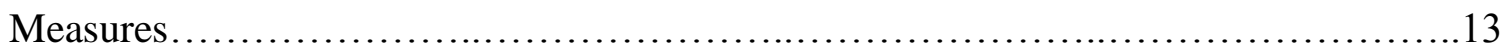

Procedure................................................................. 15

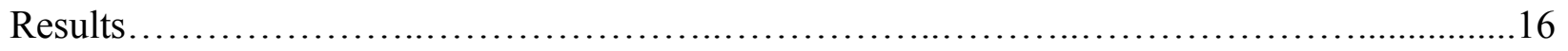

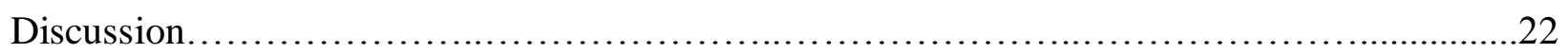

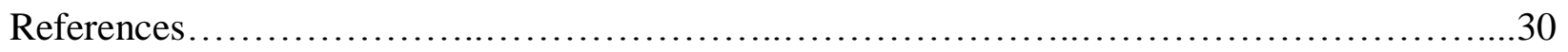

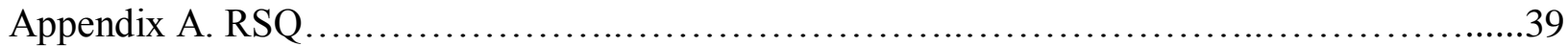




\section{List of Tables}

Table 1. Cluster analysis of coping responses for violent stressors. . ............. 17

Table 2. Cluster analysis of coping responses for school stressors............. 18 


\section{List of Figures}

Figure 1. Interaction between Violent Stressors and Coping Group on Internalizing

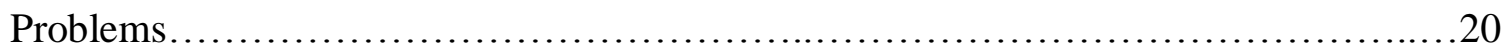




\begin{abstract}
Low-income urban African American youth experience multiple uncontrollable stressors (e.g. community violence) that may then impact the severity of controllable stressors (e.g. school stressors) and combine to produce negative life outcomes. In light of these negative outcomes, it is important to understand individual protective factors, and the coping response in particular. Past research has emphasized the advantages of primary control engagement coping, but recent evidence suggests that low-income urban African American youth facing complex and uncontrollable stressors may benefit more from disengagement strategies in response to uncontrollable stressors. Although it is expected this population would additionally benefit from applying engagement strategies to controllable stressors, it is unclear how well these youth are able to match their coping responses to specific stressors, namely violent versus school stressors.

This study investigated four primary research questions: 1) Do low-income urban African American youth perceive different levels of control over uncontrollable (i.e. violent) versus controllable (i.e. school) stressors? 2) Does the level of violent stressors predict the level of school stressors experienced by these youth? 3) What patterns of coping strategies emerge across violent and school stressors and how does level of each stressor impact the coping response? 4) What direct effects do level of each stressor and the coping response have on outcomes (i.e. school problems, internalizing problems, and personal adjustment) and does the coping response serve as a moderator of the relation between stressors and outcomes? Secondary research questions addressed differences in each variable of interest by age and gender.

Participants of this study were 143 Black or African American and Biracial/Multiracial youth between ages seven and 13 who completed a battery of measures including the Response to Stress Questionnaire (RSQ) as a measure of stressors and coping and the Behavior Assessment
\end{abstract}


System for Children (BASC) as a measure of outcomes. Results indicated slightly lower levels of perceived control over violent versus school stressors, with higher levels violent stressors significantly predicting higher levels of school stressors. Cluster analysis revealed two coping typologies for each type of stressor, with avoidance and distraction in response to violent stressors and problem solving, cognitive restructuring, and social support in response to school stressors generally emerging as the most adaptive in terms of BASC outcomes. The coping response significantly differed based on level of each stressor, and coping moderated the relationship between violent stressors and internalizing problems such that acceptance and cognitive restructuring for youth exposed to the highest levels of violence was associated with lower internalizing problems. 
Overcoming Exposure to Complex Stressors: An Examination of Protective Coping Mechanisms for Low-Income Urban African American Youth

Low-income urban African American youth face a broad range of severe and chronic stressors, including financial barriers, unstable housing and home life, lack of educational resources, and community violence, all of which stem from systemic stressors such as racism and discrimination (Brooks-Gunn, Duncan, \& Maritato, 1997; McLoyd, 1998; Bell \& Jenkins, 1993; Overstreet, 2000; Simons et al., 2002; Swanson et al., 2003; Spencer, 1990). These and other stressors that youth may confront are often divided into controllable (e.g. academic) and uncontrollable (e.g. violence) stressors based on how much personal influence youth have over the stressor. For example, doing poorly on a test in school would traditionally be classified as a controllable stressor as the student is expected to be able to change the situation by studying more to improve their grade. On the other hand, when that same student attempts to study at home, they may hear gunshots outside, a stressor they are unable to change or control that may then impact their ability to study. In this way, many such controllable stressors are often compromised by uncontrollable stressors faced by low-income urban African American youth, leaving the question of how youth operate within these blurred lines of controllability when confronted with a stressor.

To better understand the complicated nature of controllable and uncontrollable stressors, it is essential to consider the complex interplay of modern and historical systems of inequality in the United States (Sanchez, Lambert, \& Cooley-Strickland, 2013). It is well-established that African American youth are more likely to score lower on standardized tests of achievement than White youth, a finding referred to as the "achievement gap" (Dobbie \& Fryer, 2011). Without understanding context, it may be easy to claim that because school stressors are considered to be controllable, African American youth have no reason to be performing below average and are 
simply making poor decisions. However, this argument quickly dissolves when considering the pathways leading up to this achievement gap, with Chicago as a striking example.

As African American families migrated to Chicago between the 1930s and 1960s, they were met with housing discrimination practices that forced them into predatory contracts and created segregated neighborhoods, leading to the devaluation of their properties as many families were evicted only for the next African American family to be victimized (Coates, 2017). When White families began avoiding these neighborhoods, businesses fled and the neighborhoods further lost their value, beginning to deteriorate with no infrastructure to support them. Beyond housing discrimination, at the same time, African American families faced employment and pay discrimination, leading them to take lower-end jobs with difficult hours that then left less time for child monitoring and parenting (Coates, 2017). With limited economic power, African American neighborhoods in Chicago were offered few educational resources and were left with drastically underfunded schools, with much of the city's school funding being determined by zoned neighborhood property taxes (Turner et al., 2016). Meanwhile, African American men in particular became targets of mass incarceration and police brutality, with all these factors coming together to fuel hopelessness, frustration, and the need to take ownership of something after being stripped of all power (Coates, 2017). As a result, gangs began to form and attract unmonitored youth who saw few educational or economic opportunities and little or no benefits of their parents' labor. Community violence subsequently became an immediate concern for youth, impacting their ability to focus on their educations (Coates, 2017). Most importantly, all of these stressors and pathways are not merely indicators of a troubling past, but rather remain as today's reality. For low-income African American youth living in Chicago, stressors cannot so 
easily be categorized by controllability, making it essential to understand the interactions among multiple stressors and the corresponding responses contributing to different outcomes.

Of the aforementioned stressors, exposure to community violence is of particular concern because of its heightened prevalence in urban African American communities and far-reaching effects on functioning across multiple domains (Bureau of Justice Statistics, 2012; Overstreet, 2000). The issue of community violence is magnified for youth residing in Chicago, where 80 percent of homicide victims between 2015 and 2016 were African American, with over half of those victims being men between the ages of 15 and 34 (Kapustin et al., 2017). This is especially concerning given that African Americans only represent approximately one-third of the city's population, and African American men between the ages of 15 and 34 only represent four percent of the population (Kapustin et al., 2017). Although children do not appear to be the most at-risk for becoming victims of violence, research conducted within low-income neighborhoods of Chicago has estimated that children between sixth and eighth grade are exposed to about six violent incidents a week (Richards et al., 2015). Even younger children may be exposed to similar levels of violence, as 77 percent of Chicago's gun homicides and shootings in 2016 took place on the street or in an alley, largely concentrated within low-income African American neighborhoods (Kapustin et al., 2017).

Exposure to community violence, whether it be direct victimization or witnessing or even hearing about a violent event, has serious implications for the health and development of African American youth (Elsaesser, Gorman-Smith, Henry, \& Schoeney, 2017). Youth may display more externalizing behaviors in response to community violence in an effort to cope or protect themselves from being victimized, but acting aggressively may rather put them at a heightened risk of violence exposure (Cassidy and Stevenson, 2005; Cooley-Strickland et al., 2011; 
Salzinger et al., 2008; Sanchez, Lambert, \& Cooley-Strickland, 2013). Youth exposed to community violence may be more likely to perpetrate violence as well (Gorman-Smith, Henry, \& Tolan, 2004). Conversely, community violence exposure is also associated with the development of post-traumatic stress and internalizing symptoms (Fowler, Tompsett, Braciszewski, Jacques-Tiura, \& Bates, 2009; Margolin \& Gordis, 2000). Beyond physical and mental health, community violence has been independently associated with problems with school engagement and academic achievement, including lower reading ability, grades, standardized test scores, and attendance (Delaney-Black et al., 2002; Janosz et al., 2008; Mathews, Dempsey, \& Overstreet, 2009; Burdick-Will, 2016; Elsaesser, Gorman-Smith, Henry, \& Schoeney, 2017).

While community violence has been shown to directly impact both mental health and school performance, a growing body of literature suggests that psychological distress resulting from exposure to community violence may serve as a precursor to negative academic outcomes. Three studies assessing this relationship revealed that a variety of psychological symptoms mediated the relationship between community violence and school-related measures (i.e. engagement, student-teacher connectedness, GPA, and test scores) (Borofsky, Kellerman, Baucom, Oliver, Margolin, 2013; Voisin, Neilands, \& Hunnicutt, 2011; Mathews, Dempsey, \& Overstreet, 2009). Other studies have noted decreased self-efficacy and concentration following exposure to violence as contributors to academic problems, suggesting that community violence has compounding effects on youth functioning with academic issues revealing themselves over time (McMahon, Felix, Halpert, \& Petropoulos, 2009; Pynoos \& Nader, 1988). Additional research has demonstrated evidence of a bidirectional relationship between psychological distress and school problems, such that higher psychological distress independently predicts lower future school engagement and achievement, and lower school engagement and 
achievement independently predicts higher psychological distress (Bond et al., 2007; Fergusson \& Woodward, 2002; Rothon et al., 2009; Shochet, Dadds, Ham, \& Montague, 2006; Wang \& Peck, 2013).

As not all youth exposed to community violence and multiple other stressors experience severe consequences of psychological distress and academic difficulties, it is essential to uncover and understand potential protective factors that could stem this pathway. One such factor is the stress response - and adaptive coping in particular. Research has conceptualized coping in hundreds of different ways (Skinner, Edge, Altman, \& Sherwoord, 2003), but Compas and colleagues have defined instances of coping as "regulatory efforts that are volitionally and intentionally enacted specifically in response to stress" (Compas, Connor-Smith, Saltzman, Thomsen, \& Wadsworth, 2001). Their model accounts for both voluntary and involuntary responses to stress, delineating coping as just one facet of the stress response. Within the category of coping, the model separates responses into engagement (i.e. physical or mental interaction with the stressor) and disengagement (i.e. physical or mental separation from the stressor) coping. Coping is then further divided into primary and secondary control strategies, which represent modifying either some part of the environment or the self in response to a stressor (Connor-Smith, Compas, Wadsworth, Thomsen, \& Saltzman, 2000). Primary control engagement coping includes strategies such as problem solving, emotional regulation, and emotional expression, while secondary control engagement coping includes positive thinking, cognitive restructuring, and acceptance. Primary control disengagement coping includes avoidance and denial, while secondary control disengagement coping includes wishful thinking and distraction. This model also takes into consideration that certain coping strategies or combinations of strategies may be more adaptive than others depending on the person or 
situation, noting that "no pattern of responses to stress is assumed to be universally helpful or detrimental" (Connor-Smith, Compas, Wadsworth, Thomsen, \& Saltzman, 2000). Therefore, it is important to consider individual factors as well as the interaction of multiple coping responses and multiple different types of stressors to determine what constitutes a successful coping response.

Research has shown that children begin showing more secondary control disengagement techniques such as distraction in late childhood, but by late adolescence are able to engage in a wide variety of approaches in response to stressors (Donaldson, Prinstein, Danovsky, \& Spirito, 2000; Skinner \& Zimmer-Gembeck, 2007). The transition to adolescence, between ages 8 and 12, has been identified as a particularly important period when coping develops rapidly (Skinner \& Zimmer-Gembeck, 2007). However, as many past studies addressing these developmental differences have been conducted with primarily White samples, the findings may not accurately reflect the experiences of African American youth, particularly when considering the constellation of stressors specific to these youth. Research specific to African American adolescents has reported age-related increases in secondary control engagement coping strategies including cognitive reappraisal and positive thinking, but earlier developmental stages of coping are lesser known (Tolan, Gorman-Smith, Henry, Chung, \& Hunt, 2002).

Another important source of differences in coping responses is gender; in general, females appear to use both engagement and disengagement coping strategies more frequently than males, and social support in particular (Compas, Malcarne, \& Fondacaro, 1988; Tolan, Gorman-Smith, Henry, Chung, \& Hunt, 2002). Specific to low income urban African American youth, boys have been found to use more distraction and avoidance disengagement strategies, while girls rely more on support-seeking strategies (Chandra \& Batada, 2006; Grant et al., 2000; 
Tolan, Gorman-Smith, Henry, Chung, \& Hunt, 2002). Because of gender-based socialization practices, African American boys may also be more likely than girls to engage with violencerelated stressors and report using confrontation strategies (Sanchez, Lambert, \& CooleyStrickland, 2013; Voisin, Bird, Hardestry, \& Shiu, 2011).

Early coping research with White middle-class youth indicated primary control engagement as the most adaptive means of coping, while disengagement coping was consistently associated with negative outcomes (Wadsworth, 2015). As a result, primary control engagement coping strategies were traditionally upheld as the ideal, but as research expands to more diverse populations, the case is becoming much less clear. Recent studies on African American youth have revealed a complicated relationship between coping responses and various life outcomes, such that these youth have often been described as "complex copers," utilizing a wider variety of coping strategies than White youth (Gaylord-Harden, Gipson, Mance, \& Grant, 2008). In many cases, research has indicated that disengagement coping often emerges as most adaptive for this population in contrast to previous conceptions (Compas, Connor-Smith, Saltzman, Thomsen, \& Wadsworth, 2001). Because of the increased risk for exposure to severe and chronic uncontrollable stressors, this population may not benefit from taking action to reduce a stressor beyond their control. In fact, research with African American youth has shown that direct engagement with an uncontrollable stressor, namely community violence, may lead to more emotional distress and feelings of hopelessness as well as increased risk of exposure to further violence (Grant et al., 2000; Landis et al. 2007; Newcomb \& Harlow, 1986). On the other hand, disengagement coping in African American youth facing uncontrollable stressors has been largely associated with more positive outcomes (Dempsey, 2002; Dempsey, Overstreet, \& Moely, 2000; Edlynn, Gaylord-Harden, Miller, \& Richards, 2008; Grant et al., 2000). 
Given the complicated nature of stressors, it is unsurprising that the coping response is not only affected by individual factors, but may also vary substantially by context. For instance, exposure to community violence may require a different response than an academic stressor such as failing a test or having trouble finishing a homework assignment on time (Clarke, 2006). As discussed, disengagement coping processes, such as distraction and avoidance, may be most effective for responding to community violence and other uncontrollable stressors (Compas, Connor-Smith, Saltzman, Thomsen, \& Wadsworth, 2001). In contrast, most of the research suggests that when responding to controllable stressors such as difficulties with school, children fare best when they activate engagement strategies such as problem solving and social support (Causey \& Dubow, 1992; Griffith, Dubow, \& Ippolito, 2000; Valentiner, Holahan, \& Moos, 1994). However, exposure to chronic uncontrollable stress may lead youth to perceive typically controllable stressors, such as those related to school, as uncontrollable. Research suggests that when school stressors are perceived as uncontrollable, youth are less likely to match engagement strategies to the school stressors, despite the known benefits of engagement for school stress (Griffith, Dubow, \& Ippolito, 2000). Based on these findings, in the context of the multitude of stressors faced by low-income urban African American youth, it is unclear to what extent these youth are able to successfully match their coping responses to a specific stressor.

Looking more specifically at outcomes associated with coping, several studies have assessed low-income urban African American youth exposed to uncontrollable stress and community violence, although the literature is yet to properly address coping with controllable stressors, such as school stress, for this population. One study by Grant and colleagues (2000) found that, in a sample of sixth through eighth grade youth responding to chronic uncontrollable 
stress, only boys fared better when using disengagement coping strategies, as evidenced by lower externalizing problems. However, a study of third through fifth grade youth found that disengagement coping strategies were protective for girls exposed to violence, but not for boys exposed to the same stressors (Sanchez, Lambert, \& Cooley-Strickland, 2013). Further complicating the known effects of disengagement coping, another study identified that disengagement coping in response to uncontrollable stress in sixth grade predicted higher levels of anxiety at the time of the study, but that individuals who reported use of disengagement coping in sixth grade later showed less anxiety in seventh grade compared to those who did not use such strategies (Edlynn, Gaylord-Harden, Miller, \& Richards, 2008). Although the evidence suggests disengagement coping may be beneficial in situations of uncontrollable stress for lowincome urban African American youth, the conflicting findings in the literature warrant further testing to better understand the role of disengagement coping. Furthermore, as research has failed to expand upon engagement coping for school-related stressors in this population, it is crucial to investigate the effectiveness of such strategies and how much youth differentiate between uncontrollable and controllable stressors when applying coping strategies that may be linked to positive or negative outcomes.

\section{Rationale}

The current study seeks to understand the dynamics between stress and coping mechanisms in predicting psychological and school-related outcomes for low-income urban African American youth, who experience a unique constellation of stressors and patterns of coping, yet remain a largely understudied population. The uncontrollable stressor of exposure to community violence may influence the manifestation of controllable stressors, and school stress in particular. Subsequently, heightened levels of these stressors have been linked to 
psychological distress and school problems, with psychological distress often serving as a precursor of lower academic performance. Furthermore, the literature suggests that disengagement coping may have a buffering effect on negative psychological and academic outcomes associated with exposure to community violence, whereas engagement coping with school stressors may be protective against these outcomes. Despite the importance of understanding the role of coping, limited research has compared coping responses across these situations, and it is unknown how much the coping response may alter the effects of different stressors on school performance and psychological well-being. Additionally, due to the complex relationship between uncontrollable and controllable stressors, this population may face difficulties in appropriately matching coping responses, such that a limited number of youth may be experiencing the protective effects of matched coping responses. Delineating the effects of different stressors, coping responses, and outcomes for low-income urban African American youth may help create more contextually informed interventions targeting the coping behaviors that best work for this population to bolster the coping response as a protective factor.

\section{Statement of Research Questions}

Research Question I: Do low-income urban African American youth perceive different levels of control over uncontrollable (i.e. violent) versus controllable (i.e. school) stressors?

Research Question II: Does the level of violent stressors predict the level of school stressors experienced by these youth?

Research Question III: What patterns of coping strategies emerge across violent and school stressors and how does level of each stressor impact the coping response?

Research Question IV: What direct effects do level of each stressor and the coping response have on outcomes (i.e. school problems, internalizing problems, and personal 
adjustment) and does the coping response serve as a moderator of the relation between stressors and outcomes?

Research Question V: Do perceived control, stressors, and coping differ by age and gender?

\section{Method}

\section{Participants}

Participants of this study were 143 youth (55.6 percent female) between ages seven and $13(M=10.1)$ who were enrolled at baseline in a coping-based mentoring intervention between fall of 2015 and fall of 2017. A total of 93.7 percent of the youth identified as Black or African American, while the remaining 6.3 percent described themselves as Biracial or Multiracial.

\section{Setting}

All participants were recruited from three elementary schools in the Englewood and Auburn-Gresham communities on the south side of Chicago. As a product of decades of redlining and other forms of racial discrimination, both communities are primarily African American and consistently struggle with some of the highest homicide rates in Chicago, as well as averaging households 42.2 percent and 24.5 percent below the poverty line respectively (Chicago Tribune, 2017). The three schools reflect these demographics, with student bodies that are between 96 and 98 percent Black or African American, and over 95 percent low-income (Chicago Public Schools, 2017). Student attainment is below the national average for all three schools and students on average rated the safety of their school and surrounding areas as weak or very weak (Chicago Public Schools, 2017).

\section{Measures}


Stressors. Two versions of the Response to Stress Questionnaire (RSQ; Conner-Smith, Compas, Wadsworth, Thomsen, \& Saltzman, 2000) were used to assess violent stressors and school stressors. Each version includes a checklist of nine stressors occurring in the past six months. Youth report the prevalence of each stressor on a four-point scale from "not at all" to "a lot." Examples of violent stressors include "Seeing someone else get threatened with violent words," "Getting threatened with violent words yourself, and "Seeing someone seriously hurt by another person." Examples of school stressors include "Doing badly on a test or paper," "Not understanding classes," and "Not having your homework done."

Perceived Control. A single item on the Response to Stress Questionnaire (RSQ; Conner-Smith, Compas, Wadsworth, Thomsen, \& Saltzman, 2000) assesses perceived control relative to each stressor following completion of the nine-stressor checklist. The item asks, "How much control do you think you have over the problems you just chose?" and includes a fourpoint scale from "none at all" to "a lot."

Coping Responses. A modified version of the RSQ (RSQ; Conner-Smith, Compas, Wadsworth, Thomsen, \& Saltzman, 2000) was used to categorize coping responses to violence and school stress. Participants are asked to report on their use of coping responses specific to each stressor on a four-point scale from "not at all" to "a lot." Sample items include "I try to change what is happening" and "I try to get my mind off the situation by doing or thinking about something else (like playing a sport or watching T.V.).” The coping responses assessed include both primary and secondary engagement and disengagement strategies, and were more specifically categorized into problem solving, cognitive restructuring, acceptance, distraction, avoidance, and social support seeking. Each of these categories was represented by two questions, the scores for which were then summed. Prior to analyses, each youth's scores were 
averaged across all coping responses and then this mean was subtracted from each of the youth's individual coping response scores so that these scores reflected their relative emphasis in the youth's overall coping response profile.

BASC Outcomes. The Behavior Assessment System for Children: Self-Report of Personality (BASC-2 and BASC-3; Reynolds \& Kamphaus, 2004; Reynolds \& Kamphaus, 2015) was used to generate the School Problems, Internalizing Problems, and Personal Adjustment composites as measures of psychological and school-related issues. Both measures demonstrate strong psychometric properties, with high internal consistency, test-retest reliability, construct validity, and criterion-related validity (Reynolds \& Kamphaus, 2004; Reynolds \& Kamphaus, 2015). The measure uses a four-point Likert scale response set with options of "Never," "Sometimes," "Often," and "Almost Always." As both the BASC-2 and BASC-3 were used across two age ranges, T-scores were chosen for analysis to promote standardization across measures. The School Problems composite consists of items related to attitude toward school and teachers, while Internalizing Problems includes items assessing atypicality, locus of control, social stress, anxiety, depression, and sense of inadequacy. Personal Adjustment is a measure of relations with parents, interpersonal relations, self-reliance, and self-esteem.

\section{Procedure}

Participants were recruited as part of the baseline for a school-based intervention at three elementary schools through flyers and contact sheets handed out in classrooms. Once a family's contact information was obtained, the family was contacted by phone and invited to an in-person information session and baseline survey at the child's school. Both the child and a caregiver were required to attend one of these sessions in order to formally enroll and complete the consent process. At this time, youth were given a battery of measures via including the RSQ and BASC 
SRP through an online survey platform. Families were also asked to provide demographic information, including race/ethnicity, age, and gender. Youth were compensated $\$ 30$ in gift cards for completing the survey.

\section{Results}

\section{Perceived Control}

Perceived control over violent stressors and control over school stressors were moderately and positively correlated $(r=0.476, p<0.001)$, but a paired samples t-test indicated a significant difference between perceived control over violent and school stressors $(t 142=-$ $2.069, p=.04)$. On average, perceived control over violent stressors was .203 points lower than perceived control over school stressors (95\% CI [-.397, -.009]). Despite lower reported control over violent stressors, both stressors were rated with low levels of perceived control averaging to between "a little" and "some." There were no differences in perceived control based on level of either stressor, gender, age, school attended, or cohort. Age categories were formed by dividing youth into three approximately equal sized groups: ages seven through nine, age 10, and ages 11 through 13. These categories were determined based on the age distribution of the sample, as there were too few participants for the younger and older ages to allow for comparison if not combined with the adjacent ages. Interestingly, a chi square test of independence showed a nonsignificant trend $(p=.081)$ by age for perceived control over school problems, such that 30 percent of youth ages seven through nine indicated having no control over their school problems as opposed to 17 percent of 10-year-olds and 18 percent of 11-through 13-year-olds.

\section{Stressors}

Multiple regression analysis was used to test if levels of violent stressors significantly predicted levels of school stressors. It was found that exposure to violent stressors significantly 
predicted school stressors $(\beta=.54, p<.001)$. The results of the regression indicated violent stressors explained $28.8 \%$ of the variance in school stressors; $R^{2}=.288, F(1,141)=56.94, p<$ .001 . Based on the average sums of violent stressors $(M=15.08)$ and school stressors $(M=$ 16.16), exposure to both stressors equated to "a little;" however, it should be noted that 74.1 percent of the sample endorsed witnessing some degree of community violence in the past six months, while 51.3 percent of the sample endorsed personal experiences of victimization. Further assessing influences on both stressors, independent samples t-tests and one-way analysis of variance (ANOVA) indicated no significant differences in levels of school stressors, violent stressors overall, or witnessing and victimization by age, gender, or cohort. However, there was a significant difference based on school attended such that participants at one school reported higher levels of exposure to both school stressors and violent stressors $(F(2,140)=4.702, p=$ $.011)$ and school stressors $(F(2,140)=4.066, p=.019)$ in comparison to the other two schools.

\section{Coping Response}

Two-step cluster analysis was used to test for groupings based on use of coping strategies in response to violent and school stressors. Due to the number of coping variables and limited sample size, analyses were conducted separately for violent and school stressors. Cluster analysis revealed two distinct coping groups for violent stressors: 1) cognitive restructuring and acceptance $(N=67)$ and 2$)$ avoidance and distraction $(N=65)$. Two distinct coping groups were found for school stressors as well: 1) problem solving, cognitive restructuring, and social support $(N=74)$ and 2$)$ avoidance and acceptance $(N=62)$.

Table I.

Cluster analysis of coping responses for violent stressors

\begin{tabular}{|c|c|c|c|c|c|}
\hline & Group 1 & $N$ & Group 2 & $N$ & $\begin{array}{l}\text { Predictor } \\
\text { importance }\end{array}$ \\
\hline Avoidance & -0.25 & 67 & 1.72 & 65 & 1.0 \\
\hline
\end{tabular}




\begin{tabular}{lrrrrr} 
Cognitive & & & & & \\
Restructuring & 0.11 & 67 & -1.15 & 65 & 0.8 \\
Distraction & -0.06 & 67 & 1.32 & 65 & 0.8 \\
Acceptance & 0.54 & 67 & -0.41 & 65 & 0.4 \\
Problem Solving & 0.15 & 67 & 0.32 & 65 & 0.0 \\
Social Support & 0.29 & 67 & 0.18 & 65 & 0.0 \\
\hline
\end{tabular}

Table II.

Cluster analysis of coping responses for school stressors

\begin{tabular}{lrrrrr} 
& & & & \multicolumn{2}{c}{$\begin{array}{c}\text { Predictor } \\
\text { importance }\end{array}$} \\
\hline Problem Solving & 1.31 & 74 & -0.18 & 62 & 1.0 \\
Avoidance & -0.6 & 74 & 0.17 & 62 & 0.6 \\
Cognitive Restructuring & 0.47 & 74 & -0.09 & 62 & 0.2 \\
Acceptance & -0.25 & 74 & 0.25 & 62 & 0.2 \\
Social Support & 0.44 & 74 & 0 & 62 & 0.2 \\
Distraction & 0.03 & 74 & 0.11 & 62 & 0.0 \\
\hline
\end{tabular}

Using the defined coping groups, a chi square test of independence was performed to examine the relation between coping and age. A significant relation was found between age and coping with school stress such that 60 percent of youth aged seven through nine used more avoidance and acceptance when faced with school stress compared to 32 percent of 10-year-olds and 48 percent of youth between ages 11 and $13 ; \mathrm{X}^{2}(2, N=136)=7.98, p=.018$. Additional chi square tests showed no significant differences in coping group by gender or perceived control. A series of independent samples t-tests revealed a significant association between level of each stressor and coping membership, such that the group that used more cognitive restructuring and acceptance for violent stressors showed higher levels of exposure to violent stressors $(M=16.58)$ relative to the avoidance and distraction group $(M=13.72) ;(t 122.542=2.57, p=.011)$. For school stressors, youth showed lower levels of such stressors within the problem solving, cognitive restructuring, and social support coping group $(M=15.01)$ compared to the avoidance and acceptance group $(M=17.77) ;(t 134=-2.499, p=.014)$. 


\section{Stressors x Coping Response}

Coping membership for each stressor was dummy coded and assessed as a moderator of the relationship between the level of the stressor and three outcomes of interest (school problems, internalizing problems, and personal adjustment). Six regression analyses were conducted to assess each of the three outcomes for both school and violent stressors and their associated coping groups. Gender, school, and age were controlled in each model.

School Problems. The first moderation model for school problems included exposure to violent stressors and coping group (based on response to violent stressors). These variables and their interaction in addition to gender, school, and age accounted for a significant amount of variance in school problems; $R^{2}=.223, F(8,117)=4.207, p<.001$. Results indicated violent stressors $(\beta=.496, p=.030)$ directly predicted higher school problems, but membership in the cognitive restructuring and acceptance group did not reach significance. Control variables and the interaction between exposure to violent stress and coping were also nonsignificant.

A second moderation model predicting school problems included school stressors and coping group (based on response to school stressors). These predictors and their interaction along with the control variables explained a significant amount of variance in school problems; $R^{2}=$ $.177, F(8,118)=3.716, p=.003$. It was found that higher school stressors predicted higher school problems $(\beta=.411, p=.027)$, while membership in the problem solving, cognitive restructuring, and social support coping group was not significant. Gender effects were significant such that males tended to report higher school problems $(\beta=.3 .899, p=.030)$. The interaction between school stressors and coping group was nonsignificant.

Internalizing Problems. The models assessed for internalizing problems mirrored the school problems models, beginning with violent stressors and coping with violence. These 
predictors and their interaction in conjunction with the control variables accounted for a significant amount of variance in internalizing problems; $R^{2}=.276, F(8,115)=5.479, p<.001$. It was found that exposure to violent stressors $(\beta=1.160, p<.001)$ and membership in the cognitive restructuring and acceptance group $(\beta=14.428, p=.005)$ significantly predicted higher internalizing problems, while gender was not significant. A significant difference was found by age such that older youth showed lower internalizing problems $(\beta=-5.029, p=.037)$. Most notably, the interaction between violent stressors and coping was significant, such that youth who reported high levels of violent stressors and responded with cognitive restructuring and acceptance showed a reverse pattern of lower internalizing problems $(\beta=-.715, p=.025)$.

Figure I.

Interaction Between Violent Stressors and Coping Group on Internalizing Problems

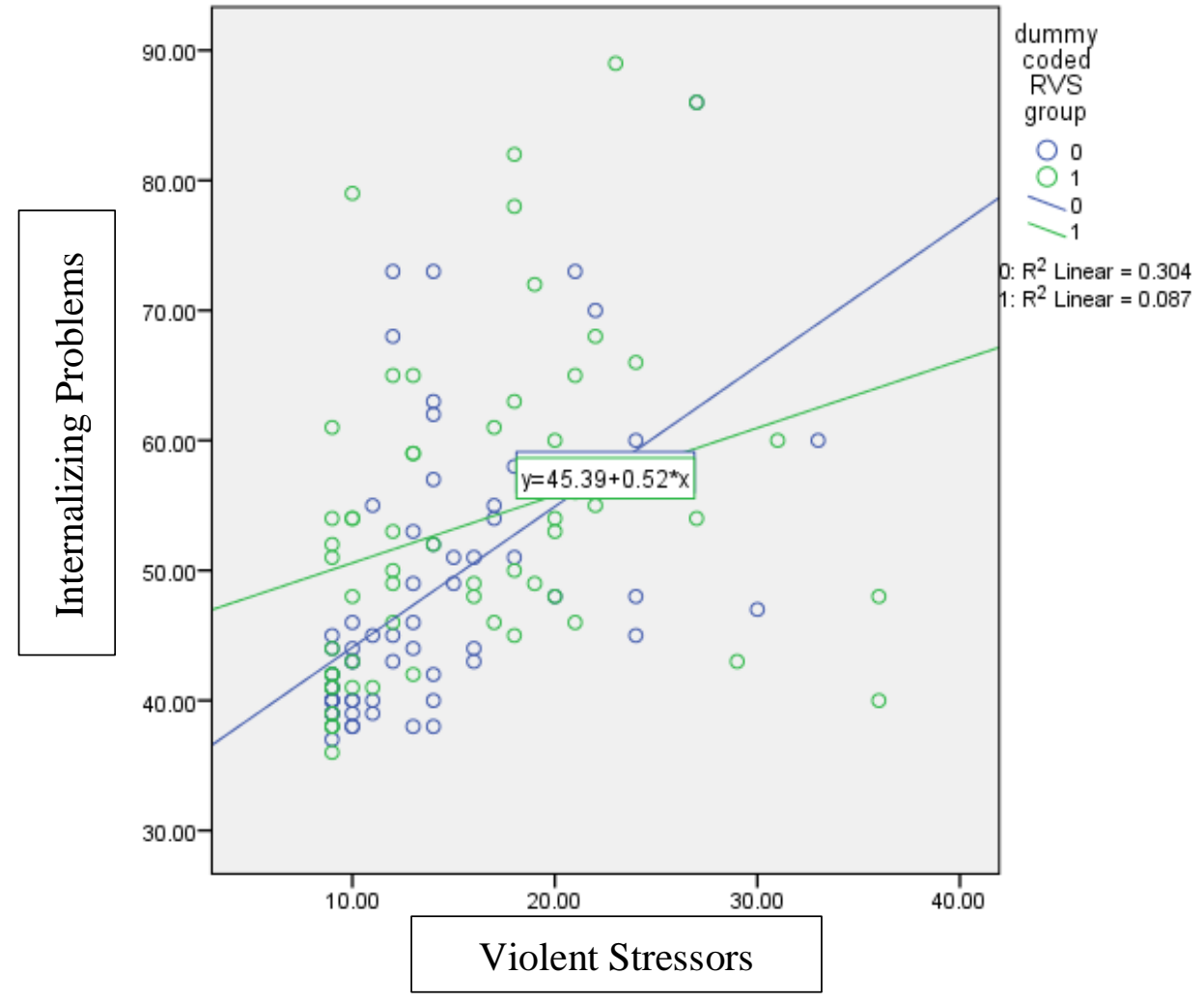

a. Dummy code of 0 (blue line) represents the avoidance and distraction group.

b. Dummy code of 1 (green line) represents the cognitive restructuring and acceptance group.

Note: Minimum score on RSQ is 10 
The moderation model assessing school stressors, coping, and their interaction as predictors of internalizing problems explained a significant amount of variance in internalizing problems with the control variables included in the model; $R^{2}=.177, F(8,118)=3.167, p=.003$. Higher school stressors predicted higher internalizing problems $(\beta=.588, p=.007)$, while membership in the problem solving, cognitive restructuring, and social support coping group was nonsignificant. Age was significant such that youth between the ages of 11 and 13 reported lower internalizing problems than the two younger age groups $(\beta=-5.006, p=.047)$. Gender, school, and the interaction between school stressors and coping were nonsignificant.

Personal Adjustment. The moderation model assessing violent stressors, coping group, and their interaction as predictors with the control variables resulted in a significant amount of variance in personal adjustment; $R^{2}=.188, F(8,114)=3.301, p=.002$. Exposure to violent stressors $(\beta=-.594, p=.015)$ directly predicted lower personal adjustment, but membership in the cognitive restructuring and acceptance group did not reach significance. Age and gender, as well as the interaction between violent stressors and coping, were also nonsignificant.

When school stressors and coping group were placed as predictors of personal adjustment, the moderation model including the control variables indicated a significant amount of variance in internalizing problems; $R^{2}=.165, F(8,117)=2.886, p=.006$. It was found that level of school stressors was nonsignificant, whereas membership in the problem solving, cognitive restructuring, and social support coping group significantly predicted higher personal adjustment $(\beta=12.300, p=.018)$. The control variables and interaction did not approach significance. 


\section{Discussion}

This study addressed four primary research questions: 1) Do low-income urban African American youth perceive different levels of control over uncontrollable (i.e. violent) versus controllable (i.e. school) stressors? 2) Does the level of violent stressors predict the level of school stressors experienced by these youth? 3) What patterns of coping strategies emerge across violent and school stressors and how does level of each stressor impact the coping response? 4) What direct effects do level of each stressor and the coping response have on outcomes (i.e. school problems, internalizing problems, and personal adjustment) and does the coping response serve as a moderator of the relation between stressors and outcomes? Additionally, based on previous research and findings in this study indicating age and gender differences across stressor exposure and the coping response, age and gender were included in all analyses.

In line with standard classifications of controllable and uncontrollable stressors, lowincome urban African American youth reported having more control over school stressors than violent stressors. Despite this difference, perceived control was reported to be fairly low across both stressors, suggesting a diminished sense of controllability for school stressors. These findings are consistent with previous research indicating controllable stressors may be seen as uncontrollable to youth who experience multiple complex and chronic stressors (Griffith, Dubow, \& Ippolito, 2000). An interesting trend emerged for perceived control such that a higher percentage of the youngest group of participants reported having no control over school problems compared to the other two age groups. This pattern may be reflective of younger youths' less developed capacities to cope with stressors, such that they may be less equipped to problem solve or seek support from others, contributing to a feeling of powerlessness over their 
school problems (Donaldson, Prinstein, Danovsky, \& Spirito, 2000; Skinner \& Zimmer-

Gembeck, 2007).

In comparing the relation between violent stressors and school stressors, unsurprisingly, experiencing higher levels of violent stressors was predictive of higher levels of school stressors. For low-income African American youth, a stressor is not likely to be an isolated event, but rather influences and is influenced by a multitude of other stressors (Coates, 2017; Turner et al., 2016). Looking broadly at average levels of violent and school stressors, the current sample appeared to report limited amounts of exposure to either stressor, and violent stressors in particular. However, in consideration of each item on the violent stressor checklist, the majority of the sample reported some degree of witnessing or victimization. Furthermore, high levels across all items would not be expected for this sample due to the young age of participants who may be exposed to fewer violent incidents than older adolescents (Kapustin et al., 2017). Perhaps for this reason, the present study found no differences in stressor exposure based on age, as the sample consisted of youth in late childhood and early adolescence, and variation in levels of both stressors may have been limited.

In terms of gender, similar to age, no differences were reported across school stressors, violent stressors, or violent stressors categorized into witnessing and victimization. While most studies have found that males are at greater risk of community violence exposure in general (Bureau of Justice Statistics, 2011; Cooley-Quille, Boyd, Frantz, \& Walsh, 2001) and across both victimization (Ceballo, Dahl, Aretakis, \& Ramirez, 2001) and witnessing (Selner-O’Hagan et al., 1998), the opposite pattern has also been observed with females reporting more of both types of exposure (Richards et al., 2015). Based on these mixed findings, and the lack of gender differences in the current study, it remains unclear how gender may relate to exposure to 
stressors in this population. Lastly, as is consistent with prior research, violent stressors and academic stressors were direct predictors of worse outcomes across the board, including more school problems (Delaney-Black et al., 2002; Janosz et al., 2008; Mathews, Dempsey, \& Overstreet, 2009; Burdick-Will, 2016; Elsaesser, Gorman-Smith, Henry, \& Schoeney, 2017) as well as post-traumatic stress and internalizing problems (Fowler, Tompsett, Braciszewski, Jacques-Tiura, \& Bates, 2009; Margolin \& Gordis, 2000).

For the response to violent stressors, cluster analysis indicated two coping groups based on youths' relative emphases on different coping responses. The first group was characterized by heightened use of two secondary control engagement strategies: cognitive restructuring and acceptance. The second group reported more disengagement strategies in the form of avoidance and distraction. Interestingly, youth who reported experiencing higher levels of violent stressors were more likely to be in the cognitive restructuring and acceptance group. One possible explanation for this finding is that violent stressors may be so proximate that disengagement becomes too challenging and youth have to confront the stressor in some way or acknowledge its presence.

In consideration of the three outcomes assessed in this study, the avoidance and distraction group consistently performed better than the cognitive restructuring and acceptance group with lower levels of school problems and internalizing problems and higher personal adjustment. These findings mirror research indicating disengagement coping strategies, such as distraction and avoidance, are most adaptive for responding to community violence and other uncontrollable stressors (Compas, Connor-Smith, Saltzman, Thomsen, \& Wadsworth, 2001; Dempsey, 2002; Dempsey, Overstreet, \& Moely, 2000; Edlynn, Gaylord-Harden, Miller, \& Richards, 2006; Grant et al., 2000). However, one key finding of this study indicated that, for 
internalizing problems, the interaction between level of violent stressors and coping group was significant such that youth who reported higher levels of violent stressors showed lower levels of internalizing problems if they were members of the cognitive restructuring and acceptance group. As youth were more likely to be in the cognitive restructuring group if they experienced more violent stressors, these findings suggest there may be something uniquely adaptive about secondary control engagement strategies in the face of heightened exposure to community violence. One possibility is that youth exposed to high levels of community violence may find it more difficult to avoid thinking about such a pervasive experience, and in attempting to suppress thoughts about the violence, may ultimately increase their thoughts and awareness of the violence, which may lead to higher reported internalizing problems if they maintained an avoidance strategy (Thompson, Arnkoff, \& Glass, 2011). Another important consideration is that some youth may realize that even if they successfully distract themselves or avoid thinking about the problem in the short-term, the situation will likely remain the same and they will need to find some way to assimilate their external experiences with their internal by acknowledging the violence. As these youth may be unable to prevent thoughts about the violence or stop the violence from occurring, acceptance and cognitive restructuring coping strategies may be most adaptive for youth exposed to high levels of violence to allow them to process and reconcile their experiences, which may then lead to a reduction in internalizing problems. As these findings were not replicated for school problems or personal adjustment, it appears that acceptance and cognitive restructuring strategies in response to violent stressors may be most essential to the internal experience, but further research is needed to clarify the role of these strategies.

Similar to the response to violent stressors, two groups emerged for the response to school stressors, with one group reporting more problem solving, cognitive restructuring, and 
social support and the other group endorsing more use of avoidance and acceptance. Youth experiencing heightened school stressors were more likely to be in the avoidance and acceptance group, perhaps perceiving their school problems as insurmountable. As previously described, a trend in perceived control suggested younger youth are more likely to perceive their school problems as uncontrollable, which may be tied to developmental limitations on coping resources (Donaldson, Prinstein, Danovsky, \& Spirito, 2000; Skinner \& Zimmer-Gembeck, 2007). In line with that finding, a significantly higher percentage of youth aged seven through nine were classified as members of the avoidance and acceptance group. Understandably, the problem solving, cognitive restructuring, and social support group, characterized by more engagement strategies, fared better across all outcome measures. Furthermore, being a member of the problem solving, cognitive restructuring, and social support group was a particularly important predictor of higher personal adjustment, likely because the combination of self-reliance and support seeking characterizing these strategies is required to foster personal adjustment.

As few studies have compared the coping response across different types of stressors, little is known about low-income urban African American youths' ability to match appropriate coping responses to different stressors. Based on the findings of this study, youth seem to differentiate between stressors by selecting different coping strategies for violent stressors versus school stressors; however, only 32.5 percent of the sample matched the more adaptive combination of coping strategies for each of the two stressors with 25.8 percent of the sample choosing the coping strategies associated with poorer outcomes for both stressors. The results of this study suggest that higher levels of stressor exposure and younger age may be risk factors for youth to engage in less adaptive coping strategies, but it is unclear what other individual characteristics or life experiences may contribute to coping style and how coping style continues 
to develop over time. Additionally, based on the finding that youth who reported higher levels of exposure to violent stressors and were members of the "less adaptive" coping group showed fewer internalizing problems, there may not be one answer for the ideal combination of coping strategies. Rather, even within a population facing high levels of complex stressors, adaptive coping may vary on a more individual basis based on the severity of those stressors and other factors yet to be understood.

This study has several limitations that should be addressed. As baseline data were used for all measures, the cross-sectional nature of this study prevents causal inferences from being drawn. However, the results of this study revealed interesting patterns particularly in the coping response that can be drawn on when later assessing these participants longitudinally. In terms of measures, as the Response to Stress Questionnaire was designed mainly as a means of studying the coping response, the checklist used to measure stressors may not be as comprehensive as other measures that obtain precise counts. Additionally, the self-report version of the BASC does not include a measure of externalizing problems, which have been previously found to be commonly associated with exposure to severe and chronic stressors, especially exposure to community violence (Cassidy and Stevenson, 2005; Cooley-Strickland et al., 2011; Salzinger et al., 2008; Sanchez, Lambert, \& Cooley-Strickland, 2013). Another limitation is that the sample size was insufficient for more sophisticated analyses, such as structural equation modeling. These sample size restrictions prevented this study from being able to test a comprehensive model containing a coping typology representative of the response to both stressors, as variables were separated by violent and school stressors in a series of regression analyses. Additionally, the small sample size may limit generalizability, necessitating continued assessments of stressors, coping, and outcomes to better understand their relationships. 
Future research is needed to assess changes in coping over time, particularly as youth reach adolescence and begin to experience heightened stressors while perhaps developing more advanced styles of coping. Additionally, research should evaluate protective factors associated with the more adaptive coping styles identified in this study in addition to evaluating interventions designed to promote adaptive coping to determine by what mechanisms coping can be improved. Future longitudinal research should also investigate changes in academic performance and psychological distress over time in conjunction with changes in coping and stressor exposure to better understand the long-term outcomes associated with stress and coping. Perhaps most importantly, follow-up studies should aim to determine what qualities emerge for youth who respond with the most adaptive strategies to both violent and school stressors as opposed to youth who respond with less adaptive strategies.

The results of this study contribute to the literature by comparing the coping response across two different stressors within the same sample, showing the ability of low-income urban African American youth to match coping responses based on the type of stressor. It is clear that higher levels of exposure to stressors may negatively impact the coping response, but, in some cases, as shown by the unanticipated relation between violent stressors and the cognitive restructuring and acceptance group, more severe stressors may interact with the coping response to produce better outcomes. This study has many important implications, but above all shows promise that a significant subset of youth are able to use their existing resources to identify the coping strategies that will best support them in overcoming the systems of severe and chronic stressors they interact with on a daily basis. Although these results are promising for individual intervention, it should be noted that coping with severe and chronic stressors is an individual level solution to a systems level problem and as such, interventions for this population should 
strive for multilevel change with the overarching goal of deconstructing systems of oppression. That being said, if future studies are able to further pinpoint the pathways to adaptive coping, then those findings may be incorporated into multilevel interventions to help bridge the gap between youth who are thriving and youth who are falling behind as they navigate systems of violent stressors, school stressors, and the many other complex stressors in their lives. 


\section{References}

Bell, C. C., \& Jenkins, E. J. (1993). Community violence and children on Chicago’s southside. Psychiatry, 56(1), 46-54.

Bond, L., Butler, H., Thomas, L., Carlin, J., Glover, S., Bowes, G., \& Patton, G. (2007). Social and school connectedness in early secondary school as predictors of late teenage substance use, mental health, and academic outcomes. Journal of Adolescent Health, 40(4), 357-e9.

Borofsky, L. A., Kellerman, I., Baucom, B., Oliver, P. H., \& Margolin, G. (2013). Community violence exposure and adolescents' school engagement and academic achievement over time. Psychology of violence, 3(4), 381-395.

Brooks-Gunn, J., Duncan, G. J., \& Maritato, N. (1997). Poor families, poor outcomes: The wellbeing of children and youth. Consequences of growing up poor, 1-17.

Burdick-Will, J. (2016). Neighborhood violent crime and academic growth in Chicago: Lasting effects of early exposure. Social Forces, 95(1), 133-158.

Bureau of Justice Statistics. (2011). Homicide trends in the United States, 1980 -2008: Annual rates for 2009 and 2010 (Publication NCJ 236018). Washington, DC: U.S. Department of Justice.

Bureau of Justice Statistics (2012).Violent crime against youth, 1994-2010 (Publication NCJ 240106). Washington, DC: U.S. Department of Justice.

Cassidy, E. F., \& Stevenson Jr, H. C. (2005). They wear the mask: Hypervulnerability and hypermasculine aggression among African American males in an urban remedial disciplinary school. Journal of Aggression, Maltreatment \& Trauma, 11(4), 53-74. 
Causey, D. L., \& Dubow, E. F. (1992). Development of a self-report coping measure for elementary school children. Journal of Clinical Child and Adolescent Psychology, 21(1), 47-59.

Ceballo, R., Dahl, T. A., Aretakis, M. T., \& Ramirez, C. (2001). Inner-city children's exposure to community violence: How much do parents know?. Journal of Marriage and Family, 63(4), 927-940.

Chandra, A., \& Batada, A. (2006). Exploring Stress and Coping Among Urban African American Adolescents: The Shifting the Lens Study. Preventing Chronic Disease, 3(2).

Chicago Public Schools. (2017). Retrieved September 1, 2017 from http://schoolinfo.cps.edu/schoolprofile/FindaSchool.aspx.

Chicago Tribune. (2017). Crime in Chicago. Retrieved September 25, 2017, from http://crime.chicagotribune.com/chicago/community/auburn-gresham Chicago Tribune. (2017). Crime in Chicago. Retrieved September 25, 2017, from http://crime.chicagotribune.com/chicago/community/englewood

Clarke, A. T. (2006). Coping with interpersonal stress and psychosocial health among children and adolescents: A meta-analysis. Journal of Youth and Adolescence, 35(1), 10-23.

Coates, T. (2017, August 17). The Case for Reparations. Retrieved September 25, 2017, from https://www.theatlantic.com/magazine/archive/2014/06/the-case-for-reparations/361631/.

Compas, B. E., Connor-Smith, J. K., Saltzman, H., Thomsen, A. H., \& Wadsworth, M. E. (2001). Coping with stress during childhood and adolescence: problems, progress, and potential in theory and research. Psychological bulletin, 127(1), 87. 
Compas, B. E., Malcarne, V. L., \& Fondacaro, K. M. (1988). Coping with stressful events in older children and young adolescents. Journal of consulting and clinical psychology, 56(3), 405.

Connor-Smith, J. K., Compas, B. E., Wadsworth, M. E., Thomsen, A. H., \& Saltzman, H. (2000). Responses to stress in adolescence: Measurement of coping and involuntary stress responses. Journal of consulting and clinical psychology, 68(6), 976-992.

Cooley-Strickland, M. R., Griffin, R. S., Darney, D., Otte, K., \& Ko, J. (2011). Urban African American youth exposed to community violence: A school-based anxiety preventive intervention efficacy study. Journal of prevention \& intervention in the community, 39(2), 149-166.

Cooley-Quille, M., Boyd, R. C., Frantz, E., \& Walsh, J. (2001). Emotional and behavioral impact of exposure to community violence in inner-city adolescents. Journal of Clinical Child Psychology, 30, 199 -206. doi: 10.1207/S15374424JCCP3002_7

Delaney-Black, V., Covington, C., Ondersma, S. J., Nordstrom-Klee, B., Templin, T., Ager, J., ... \& Sokol, R. J. (2002). Violence exposure, trauma, and IQ and/or reading deficits among urban children. Archives of pediatrics \& adolescent medicine, 156(3), 280-285.

Dempsey, M. (2002). Negative coping as mediator in the relation between violence and outcomes: inner-city African American youth. American Journal of Orthopsychiatry, 72(1), 102.

Dempsey, M., Stacy, O., \& Moely, B. (2000). “Approach” and "avoidance” coping and PTSD symptoms in innercity youth. Current Psychology, 19(1), 28-45. 
Dobbie, W., Fryer, R. G., \& Fryer Jr, G. (2011). Are high-quality schools enough to increase achievement among the poor? Evidence from the Harlem Children's Zone. American Economic Journal: Applied Economics, 3(3), 158-187.

Donaldson, D., Prinstein, M. J., Danovsky, M., \& Spirito, A. (2000). Patterns of children's coping with life stress: implications for clinicians. American Journal of Orthopsychiatry, 70(3), 351.

Edlynn, E. S., Gaylord-Harden, N. K., Richards, M. H., \& Miller, S. A. (2008). African American inner-city youth exposed to violence: Coping skills as a moderator for anxiety. American Journal of Orthopsychiatry, 78(2), 249.

Elsaesser, C., Gorman-Smith, D., Henry, D., \& Schoeney, M. (2017). The Longitudinal Relation Between Community Violence Exposure and Academic Engagement During Adolescence: Exploring Families’ Protective Role. Journal of Interpersonal Violence, 0886260517708404.

Fergusson, D. M., \& Woodward, L. J. (2002). Mental health, educational, and social role outcomes of adolescents with depression. Archives of general psychiatry, 59(3), 225-231.

Fowler, P. J., Tompsett, C. J., Braciszewski, J. M., Jacques-Tiura, A. J., \& Baltes, B. B. (2009). Community violence: A meta-analysis on the effect of exposure and mental health outcomes of children and adolescents. Development and psychopathology, 21(1), 227259.

Gaylord-Harden, N. K., Gipson, P., Mance, G., \& Grant, K. E. (2008). Coping patterns of African American adolescents: a confirmatory factor analysis and cluster analysis of the Children's Coping Strategies Checklist. Psychological Assessment, 20(1), 10. 
Gorman-Smith, D., Henry, D. B., \& Tolan, P. H. (2004). Exposure to community violence and violence perpetration: The protective effects of family functioning. Journal of Clinical Child and Adolescent Psychology, 33(3), 439-449.

Grant, K. E., O’Koon, J. H., Davis, T. H., Roache, N. A., Poindexter, L. M., Armstrong, M. L., ... \& McIntosh, J. M. (2000). Protective factors affecting low-income urban African American youth exposed to stress. The Journal of Early Adolescence, 20(4), 388-417.

Griffith, M. A., Dubow, E. F., \& Ippolito, M. F. (2000). Developmental and cross-situational differences in adolescents' coping strategies. Journal of youth and adolescence, 29(2), 183-204.

Janosz, M., Archambault, I., Pagani, L. S., Pascal, S., Morin, A. J., \& Bowen, F. (2008). Are there detrimental effects of witnessing school violence in early adolescence?. Journal of Adolescent Health, 43(6), 600-608.

Kapustin, M., Ludwig, J., Punkay, M., Smith, K., Speigel, L., \& Welgus, D. (2017). Gun Violence in Chicago, 2016. Chicago, IL: University of Chicago Crime Lab.

Landis, D., Gaylord-Harden, N. K., Malinowski, S. L., Grant, K. E., Carleton, R. A., \& Ford, R. E. (2007). Urban adolescent stress and hopelessness. Journal of Adolescence, 30(6), 1051-1070.

Margolin, G., \& Gordis, E. B. (2000). The effects of family and community violence on children. Annual review of psychology, 51(1), 445-479.

Mathews, T., Dempsey, M., \& Overstreet, S. (2009). Effects of exposure to community violence on school functioning: The mediating role of posttraumatic stress symptoms. Behaviour research and therapy, 47(7), 586-591. 
McLoyd, V. C. (1998). Socioeconomic disadvantage and child development. American psychologist, 53, 185.

McMahon, S. D., Felix, E. D., Halpert, J. A., \& Petropoulos, L. A. (2009). Community violence exposure and aggression among urban adolescents: Testing a cognitive mediator model. Journal of Community Psychology, 37(7), 895-910.

Newcomb, M. D., \& Harlow, L. L. (1986). Life events and substance use among adolescents: mediating effects of perceived loss of control and meaninglessness in life. Journal of personality and social psychology, 51(3), 564.

Overstreet, S. (2000). Exposure to community violence: Defining the problem and understanding the consequences. Journal of Child and Family Studies, 9(1), 7-25.

Pynoos, R. S., \& Nader, K. (1988). Psychological first aid and treatment approach to children exposed to community violence: Research implications. Journal of traumatic stress, 1(4), 445-473.

Reynolds, C.R., \& Kamphaus, R.W. (2004). Behavior assessment system for children (2nd ed.). Circle Pines, MN: American Guidance Service.

Reynolds, C. R., Kamphaus, R. W., \& Vannest, K. J. (2015). BASC3: Behavior Assessment System for Children. PscyhCorp.

Richards, M. H., Romero, E., Zakaryan, A., Carey, D., Deane, K., Quimby, D., ... \& Burns, M. (2015). Assessing urban African American youths' exposure to community violence through a daily sampling method. Psychology of Violence, 5(3), 275.

Rothon, C., Head, J., Clark, C., Klineberg, E., Cattell, V., \& Stansfeld, S. (2009). The impact of psychological distress on the educational achievement of adolescents at the end of 
compulsory education. Social Psychiatry and Psychiatric Epidemiology, 44(5), 421-427. http://doi.org/10.1007/s00127-008-0452-8

Salzinger, S., Rosario, M., Feldman, R. S., \& Ng-Mak, D. S. (2008). Aggressive behavior in response to violence exposure: is it adaptive for middle-school children?. Journal of Community Psychology, 36(8), 1008-1025.

Sanchez, Y. M., Lambert, S. F., \& Cooley-Strickland, M. (2013). Adverse life events, coping and internalizing and externalizing behaviors in urban African American youth. Journal of child and family studies, 22(1), 38-47.

Selner-O'Hagan, M. B., Kindlon, D. J., Buka, S. L., Raudenbush, S. W., \& Earls, F. J. (1998). Assessing exposure to violence in urban youth. The Journal of Child Psychology and Psychiatry and Allied Disciplines, 39(2), 215-224.

Shochet, I. M., Dadds, M. R., Ham, D., \& Montague, R. (2006). School connectedness is an underemphasized parameter in adolescent mental health: Results of a community prediction study. Journal of Clinical Child \& Adolescent Psychology, 35(2), 170-179.

Simons, R. L., Murry, V., McLoyd, V., Lin, K., Cutrona, C., \& Conger, R. D. (2002).

Discrimination, crime, ethnic identity, and parenting as correlates of depressive symptoms among African American children: A multilevel analysis. Development and Psychopathology, 14, 371-393.

Skinner, E. A., Edge, K., Altman, J., \& Sherwood, H. (2003). Searching for the structure of coping: a review and critique of category systems for classifying ways of coping. Psychological bulletin, 129(2), 216.

Skinner, E. A., \& Zimmer-Gembeck, M. J. (2007). The development of coping. Annu. Rev. Psychol., 58, 119-144. 
Spencer, M. B. (1990). Parental values transmission: Implications for the development of African-American children. Black families: Interdisciplinary perspectives, 111-130.

Swanson, D. P., Cunningham, M., \& Spencer, M. B. (2003). Black males' structural conditions, achievement patterns, normative needs, and "opportunities". Urban Education, 38(5), 608-633.

Thompson, R. W., Arnkoff, D. B., \& Glass, C. R. (2011). Conceptualizing mindfulness and acceptance as components of psychological resilience to trauma. Trauma, Violence, \& Abuse, 12(4), 220-235.

Tolan, P. H., Gorman-Smith, D., Henry, D., Chung, K. S., \& Hunt, M. (2002). The relation of patterns of coping of inner-city youth to psychopathology symptoms. Journal of Research on Adolescence, 12(4), 423-449.

Turner, C., Khrais, R., Lloyd, T., Olgin, A., Isensee, L., Vevea, B., \& Carsen, D. (2016, April 18). Why America's Schools Have A Money Problem. Retrieved September 25, 2017, from http://www.npr.org/2016/04/18/474256366/why-americas-schools-have-a-moneyproblem.

Valentiner, D. P., Holahan, C. J., \& Moos, R. H. (1994). Social support, appraisals of event controllability, and coping: An integrative model. Journal of Personality and Social Psychology, 66(6), 1094.

Voisin, D. R., Bird, J. D., Hardestry, M., \& Shiu, C. S. (2011). African American adolescents living and coping with community violence on Chicago's Southside. Journal of Interpersonal Violence, 26(12), 2483-2498.

Voisin, D. R., Neilands, T. B., \& Hunnicutt, S. (2011). Mechanisms linking violence exposure and school engagement among African American adolescents: Examining the roles of 
psychological problem behaviors and gender. American Journal of Orthopsychiatry, 81(1), 61-71.

Wadsworth, M. E. (2015). Development of maladaptive coping: A functional adaptation to chronic, uncontrollable stress. Child development perspectives, 9(2), 96-100.

Wang, M. T., \& Peck, S. C. (2013). Adolescent educational success and mental health vary across school engagement profiles. Developmental psychology, 49(7), 1266. 


\section{Appendix A}

Response to Stress Questionnaire

\section{List of possible violent stressors:}

This is a list of things about violence that children and teenagers sometimes find stressful or a problem to deal with. Please choose how much a problem the things listed below have been for you in the past 6 months.

\section{Item}

Seeing someone else get threatened with violent words.

Getting threatened with violent words yourself.

Seeing someone else get threatened with a weapon.

Getting threatened with a weapon yourself.

Seeing someone else get bothered or chased by gangs.

Being bothered or chased by gangs yourself.

Seeing someone else get beaten up or jumped

Getting beaten up or jumped yourself

Seeing someone seriously hurt by another person

\section{Answer choices}

Not at all, a little, some, a lot Not at all, a little, some, a lot Not at all, a little, some, a lot Not at all, a little, some, a lot Not at all, a little, some, a lot Not at all, a little, some, a lot Not at all, a little, some, a lot Not at all, a little, some, a lot Not at all, a little, some, a lot

\section{List of possible academic stressors:}

This is a list of things about school or schoolwork that children and teenagers sometimes find stressful or a problem to deal with. Please choose how much a problem the things listed below have been for you in the past 6 months.

\section{Item}

Doing badly on a test or paper

Getting bad grades on report cards

Not understanding classes

Not understanding homework

Teachers that yell or get angry

Having bad classes or teachers

Having trouble studying

Not having your homew ork done

Pressure from parents or teachers to perform perfectly

\section{Perceived control:}

How much control do you think you have over the problems you just chose?

\section{Answer choices}

Not at all, a little, some, a lot Not at all, a little, some, a lot Not at all, a little, some, a lot Not at all, a little, some, a lot Not at all, a little, some, a lot Not at all, a little, some, a lot Not at all, a little, some, a lot Not at all, a little, some, a lot Not at all, a little, some, a lot

\section{Coping responses:}

How have you coped with these things? Please answer the following questions as best you can. Items that assess problem-solving coping: 
2. I try to stop people from being violent. $O R$ I try to make things better at school or with my school work.

\section{Items that assess cognitive restructuring:}

3. I try to change the way I think about the situation.

4. I try to think that good things could come from the violence $O R$ my school problems.

\section{Items that assess acceptance:}

5. I try to accept the situation and comfort myself.

6. I think there is nothing I can do about the violence $O R$ my school problems, so I should try to take care of myself.

\section{Items that assess distraction:}

7. I try to get my mind off the situation by doing or thinking about something else (like playing a sport or watching T.V.).

8. I try to do something else or think about something else so that I am not thinking about the violence $O R$ my school problems.

\section{Items that assess avoidance:}

9. I try not to think about the violence $O R$ my school problems.

10. If I find myself thinking about the violence $O R$ my school problems, I try to stop.

\section{Items that assess social support:}

11. I try to get help from other people. 12. I turn to other people for help with problems with violence $O R$ my school problems.

Not at all, a little, some, a lot Not at all, a little, some, a lot

Not at all, a little, some, a lot Not at all, a little, some, a lot Not at all, a little, some, a lot

Not at all, a little, some, a lot

Not at all, a little, some, a lot

Not at all, a little, some, a lot Not at all, a little, some, a lot Not at all, a little, some, a lot Not at all, a little, some, a lot 